\title{
LA CONFIGURACION DE LA CIENCIA TEOLOGICA DE HUGO DE SAN VICTOR A TOMAS DE AQUINO
}

\author{
Elisabeth Reinhardt* \\ Josep Ignasi Saranyana*
}

SINTEESE - Nos séculos XII e XII surgiram as sumas teológicas, nas quais distingue-se uma forma literária externa, com a ordenação da matéria e o desenvolvimento do discurso, e, de outro, a forma interna, como uma idéia sistematizadora. Os autores analisam as obras da época para descobrir nelas aspectos comuns e diferenças.

PALAVRAS-CHAVE - sumas teológicas, gênero literário, sistematização, Filosofia medieval.
ABSTRACT - In the twelfth and thirteenth centuries appeared the theological summae in which we must distinguish, on the one hand, a literary form with the arrangement of the subjects and the development of the discourse and, on the other hand, the internal form, i. e, the articulation of the ideas. Many authors analyse the works of this period, in order to find common aspects and differences.

KEY WORDS - theological summae, literary genre, systematization, medieval philosophy.

\section{1 - Introducción}

Con el término "suma teológica" se quería expresar, cuando nació este género, es decir, en el paso del siglo XII al XIII, una sistematización de todo el saber teológico. ${ }^{1}$ Según Palémon Glorieux, ${ }^{2}$ una suma se define por tres caracteristicas: por aportar una visión completa de la materia que trata, por ser concisa y exacta, y por ser orgánica. No se puede afirmar que súbitamente, como un fenómeno explosivo e casi inexplicable, surgiesen una serie de obras sistemáticas con las

* Universidad de Navarra.

1 Así se expresaba Honorio de Autun (tca.1137): "Et ideo Summam totius placuit vocari, cum in ea series totius scripturae videatur summatim notari" (Summa totius de omnimoda historia, en PL 172, 189A).

2 P. GLORIEUX, Sommes, DThC, 14/2 (1941) 2342-2364.

\begin{tabular}{|l|l|l|l|l|l|}
\hline VERITAS & Porto Alegre & v. 43 & $\mathrm{n}^{2} 3$ & Setembro 1998 & p. 549-562 \\
\hline
\end{tabular}


condiciones antes descritas. ${ }^{3}$ El alumbramiento fue más bien el resultado de un proceso lento en cuyo inicio se aprecia una clara intención didáctica: ordenar de forma inteligible lo múltiple en un todo, como se ha expresado Ludwig Hödl. ${ }^{4}$ Este autor distingue, por una parte, una forma literaria de la suma que concierne la estructura externa, a la ordenación de la materia y al desarrollo del discurso (quaestio, disputatio, quaestio-articulus, etc.); y, por otra parte, habla de la forma interna de la suma que viene determinada por el Systemgedanke o la idea sistematizadora que no se deduce de un concepto, sino que ha crecido históricamente y abarca fe y moral (summa in credendis et in agendis consistit), el conocimiento de Dios y la economía de la salvación. ${ }^{5}$

Aunque se pueden distinguir perfectamente la forma literaria y la forma interna, las dos formas están íntimamente unidas, se podría decir, de un modo vital. Claramente no se trata de una construcción aprioristica que se proyecta sobre un conjunto de temas para imprimirles ese orden. Influyen sin duda tradiciones, valoraciones personales y el ambiente cultural de la época. De entrada, no parecen creativas, vitales, sino más bien construcciones frias, cuadriculadas. Cabría, pues, encuadrarlas en una categoría de literatura teológica, más o menos uniformes, de un interés simplemente historiográfico, hasta que uno se asoma a las obras individuales.

En este estudio se pretende un acercamiento al género de las sumas teológicas para descubrir aspectos comunes y diferencias, teniendo en mente posibles aspectos creativos y originales.

\section{2 - Selección de obras}

Entre el gran número de sumas teológicas que han llegado hasta nosotros, he hecho una selección según un doble criterio:

a) en primer lugar, cronológico, siguiendo su evolución desde el momento en que aparece la suma hasta su configuración definitiva;

b) en segundo lugar, por su importancia en cuanto a la novedad de planteamiento y a la difusión.

3 Cfr. M. GRABMANN, Die Geschichte der scholastischen Methode, Herder, Freiburg im Br. 19091911, 2 vols. Es especialmente interesante, para nuestro tema, el volumen segundo, donde Grabmann estudia el método teológico de Pedro Abelardo, Hugo de San Víctor (en su obra De sacramentis christianae fidei), la Summa sententiarum, y los Libri quattuor sententiarum de Pedro Lombardo. Sobre la estructura y método de Hugo de San Víctor y de la Summa sententiarum, cfr. también J. de GHELL.TNCK, Le mouvement théologique du XIIe siècle, reimpresión de Culture et Civilisation, Bruxelles: 1969, p. 180-203.

L.HÖDL, Summa, LThK, 9 (1986) 1164-1166.

5 Marie-Dominique Chenu se interesó repetidamente por el origen de la ciencia teológica, entendida según el paradigma aristotélico. Sobre este tema publicó dos obras notables: La Théologie comme science, J. Vrin, Paris 1927 (hay una edición posterior ampliada, puesta al día bibliográficamente: La teologia come scienza neI XII secolo, Jaca Book, Milano 1985); y La Théologie au XIIe siècle, J. Vrin, Paris: 1957. 
Nuestra selección abarca los siglos XII y XIII, ${ }^{6}$ y comprende, por orden cronológico, las siguientes obras:

En el contexto de las sumas, y en cuanto a su origen, conviene mencionar, quizá en primer lugar, a Pedro Abelardo. Aunque no es propiamente un "sumista", su obra es importante para el género de las sumas. Su obra madura, la Theologia scholarium, ${ }^{7}$ se sitúa entre 1137 y 1139 . Aunque no reúne todas las características de una suma, porque no abarca todo el saber teológico, en ella ya está presente un Systemgedanke amplio: fides-sacramentum-caritas, como muy bien había visto Marie-Dominique Chenu. ${ }^{8}$

En segundo lugar, desde el punto de vista cronológico, viene un trabajo de Hugo de San Víctor, terminado hacia 1140, que lleva por título De sacramentis christianae fidei. ${ }^{9}$ Aunque su rótulo no lo indique, es una veradera suma, quizá la más perfecta de las primeras. Según se expresa en el breve prólogo que antecede el libro primero, Hugo se propuso expresamente una organización del saber teológico de su tiempo, con fines didácticos: "Encadené de modo bastante breve esta suma de todas las cosas" ${ }^{10}$ Consta de dos libros, según el Antiguo y el Nuevo Testamento, es decir, según las dos Alianzas, y se inscribe en el género narrativohistórico (more historico, dice), siguiendo el hilo de la Revelación, que fue progresiva, hasta alcanzar su plenitud en Cristo. Hugo reconoce que un curso suyo anterior tuvo carácter histórico (seguramente se refiere a su De sacramentis legis naturalis et scriptae dialogus), ${ }^{11}$ por lo que ahora pretende una profundización alegórica (o sea, según el sentido espiritual) y no tanto histórica; ${ }^{12}$ pero el resultado es también histórico. ${ }^{13}$

6 Sobre este tema seguimos en gran parte un estudio hecho por J. I. SARANYANA, en J. L. ILLANES y J. I. SARANYANA, Historia de la Teología, BAC, Madrid: 1995; aporta datos de interés la monografia de A. Robles, Problemática y enfoques de la teologia medieval. Historia de las escuelas teológicas, Valencia, 1982.

7 El títuio no es de Abelardo, sino que fue acuñado por Ostlander. El propio Abelardo se refería a esta obra como Introductio ad theologiam, o simplemente Theologia. La edición critica: Petri Abaelardi opera theologica, III, Corpus Christianorum, Continuatio Mediaevalis, XIII, Turnholti 1987.

M. D. CHENU, Introduction à saint Thomas d'Aquin, J. Vrin, Paris: 1954, p. 260.

9 PL 176, 173-618. No existe aún edición critica. Está estructurada en dos libros: el primer libro (opus conditionis) abarca los misterios anteriores a la venida de Cristo; el segundo (opus restaurationis) trata de Cristo, la Iglesia, los sacramentos y los novísimos.

10 "Hanc enim quasi brevem quamdam summam omnium in unam seriem compegi" (De sacramentis christianae fidei, prologus, [PL 176,183]).

11 Cum igitur de prima eruditione sacri eloquii quae in Historica constat lectione, compendiosum volumen prius dictassem [..]" (ibidem). El De sacramentis legis naturalis et scriptae dialogus se puede consultar en PL 176, 17-42.

12 "[...] hoc nunc ad secundam eruditionem (quae in allegoria est) introducendis praeparavi [...]" (ibidem).

13 El primer libro está dividido en doce partes: el Hexaëmeron; la creación y los atributos operativos de la esencia divina; el conocimiento divino; la voluntad divina; la creación de los ánegeles y su prueba moral; la creación del hombre y su estado de integridad paradisiaca; la caída del hombre; la reparación del pecado; la institución de los sacramentos; la fe; la ley natural; la ley escrita. El segundo libro se divide en dieciocho partes: la Encarnación del Verbo y la inauguración del tiempo de la gracia; la unidad de la Iglesia; los órdenes eclesiásticos (incluidos el orden sacerdotal); los paramentos sacerdotales; la dedicación de las iglesias; el sacramento del bautismo; la confirmación sacramental; la Eucaristía; los sacramentos menores (es decir, los sacramentales); la simonia; 
Vamos a considerar también la Summa sententiarum, ${ }^{14}$ fechada poco después de 1141, año en que murió Hugo de San Víctor. La autoría no está establecida con toda seguridad, pero en cualquier caso se ha abandonado la teoría de quienes la atribuian a Hugo. Esta Summa abandona la estructura more historico, y ofrece una sistematización lineal: la Santísima Trinidad y la Encarnación; la creación en general y los ángeles; la creación en particular (el hexamerón bíblico), la creación del hombre y su caida; los sacramentos y el decálogo mosaico; el bautismo; la confirmación, penitencia, Eucaristia y extremaunción; el matrimonio (falta el tratado de las postrimerias o de los novísimos). Algunos piensan que el autor es Odón de Lucca, obispo de esta ciudad italiana entre 1138 y 1146, que escribió una sintesis teológica titulada asi. ${ }^{15}$ Por la enumeración de sus partes, que hemos ofrecido más arriba, se advierte que la sistemática de esta Summa estaría llamada a tener una influencia notable.

Entre todas las obras del siglo XII destacan particularmente los Sententiae libri quatuor ${ }^{16}$ de Pedro Lombardo, redactados entre 1142 y 1157. Llegó a ser el manual teológico más difundido en la Edad Media, después de haber sido introducido como libro de texto en la Universidad de París poco después de 1215.

Ya a comienzos del siglo XIII encontramos la Summa aurea ${ }^{17}$ de Guillermo de Auxerre, maestro secular de la primera generación parisina, redactada entre 1216 y 1229. Fue usada como texto escolástico por los primeros dominicos de París y tomada en cuenta por Alejandro de Hales, maestro secular hasta 1236. Esta Summa, la más antigua de las sumas universitarias, al menos, la primera que comenzó a escribirse, constituye una recepción académica interesantísima de los dos principales decretos (o decretales, según la terminología usada en la época) del recién clausurado Concilio Lateranense IV (1215). Nos referimos a los decretos Firmiter y Damnamus ergo. El segundo de ellos es citado expresamente, y comentado ampli-

el sacramento del matrimonio; los votos religiosos; los vicios y las virtudes; la confesión, la penitencia y la remisión de los pecados; la unción delos enfermos; la muerte o final dela vida humana; el fin del mundo o de los tiempos; el estado final (reprobación eterna y bienaventuranza eterna).

PL 176, 41-174. No existe edición crítica. consta de siete libros: 1) la Santisima Trinidad y la Encarnación; 2) la creación en general y los ángeles; 3) la creación en particular, siguiendo el hexaemeron, el pecado, los dones y virtudes; 4) los sacramentos en general y el decálogo mosaico; 5) el bautismo; 6) la confirmación, eucaristía, penitencia y extremaunción; 7) el matrimonio: aquí termina la edición de PL; el orden y los novisimos fueron añadidos por otros autores medievales. cfr. J. L. ILLANES y J. I. SARANYANA, op. cit., p. 38-39.

16 Existe edición crítica: Magistri Petri Lombardi Parisiensis Episcopi Sententiae in IV libri distinctae, Collegii S. Bonaventurae ad Claras Aquas, Grottaferrata 1971-1981, en tres volúmenes agrupados en dos tomos. Los cuatro libros están ordenados así: 1) Dios en si mismo; 2) la obra de la creación, que incluye los temas de gracia y pecado; 3) cristologia y soteriologia; 4) los sacramentos, con el apéndice sobre los novisimos.

La edición critica está hecho por J. RIBAILLIER y publicada en Spicilegium Bonaventurianum XVIXX, Roma-París 1980-1987, en 7 vols. (El volumen primero es una larga "Introduction générale", publicado al culminarse la edición crítica, en 1987, a cargo de Jean Ribaillier). El adjetivo aurea no es del autor, sino que fue añadido después como testimonio de la estima de que gozaba la obra entre los teólogos medievales. Esta suma está dividida en cuatro libros: 1) Dios en sí mismo (la Trinidad y cuestiones sobre la esencia divina), precedido por una demostración de la existencia de Dios; 2) Dios como ejemplar de la creación, las criaturas, y el pecado; 3) la cristología, las virtudes teologales y morales; 4) los sacramentos y los novisimos, incluído un estudio de la ley. 
amente, en la parte de la Summa aurea dedicada a la Santísima Trinidad (libro primero, tratado IV, capitulo IV).

Es muy interesante que la Summa aurea comience demostrando la existencia de Dios, donde se hace eco de las dos vías: a simultaneo y a posteriori. ${ }^{18}$ No han pasado en vano las polémicas sobre la tendencia panteísta (aunque de signo distinto) de David de Dinant y Amalrico de Bene, que habían salpicado la primera década del siglo XIII, hasta su proscripción por parte del Sínodo parisino de 1210 $y$, sobre todo, en le IV Lateranense; y lo que antes se consideraba como algo evidente para todo teólogo, puesto que el objeto de toda ciencia no ha de ser probado por la misma ciencia, sino por otra de rango superior, ahora, sin embargo, aparece como el primer tema al que el teólogo debe rendir atención. Veremos repetida esta opción metodológica, que también lo es epistemológica, en la Summa fratris Alexandri y, sobre todo, en la Summa theologiae aquiniana. Ello implica, no sólo un distanciamiento de los panteísmos antes aludidos, sino la convicción de que in via no es evidente la existencia de Dios y, por ello, que es necesaria su demostración (y que, además, tal demostración es posible). ${ }^{19}$

También a comienzos del siglo XIII, aunque dependiente, en parte, de la Summa aurea, destaca la Summa de bono ${ }^{20}$ de Felipe el Canciller, escrita entre 1225 y 1229. Esta obra, que es una sistematización de los artículos de la fe a partir de la noción del bien, estuvo motivada seguramente por las decisiones del Concilio IV de Letrán sobre el dualismo cátaro-albigense. En el decreto Firmiter del Laterano, que constituye una excelente profesión de fe, se afirma tajantemente que Dios es "creator omnium visibilium et invisibilium, spiritualium et corporalium" (DS 800). La materia, que es un elemento constituyente de todo lo corporal, ${ }^{21}$ no podía ser intrínsecamente mala. Por consiguiente, no había lugar para el pretendido dualismo maniqueo, ni, por otro lado, para una condena de lo material y de todo lo dependiente de la materia, como el "contrato" matrimonial. En tal contexto se

18 Cfr. J. SARANYANA, La recepción del argumento anselmiano en la Escolástica del siglo XIII (1220-1270), en VV.AA., Veritati Catholicae. Festschrift für Leo Scheffczyk, Pattloch, Aschaffenburg 1985 , p. $612-627$.

19 Cuando Aquino discuta, al comienzo de la Summa theologiae, si es evidente la existencia de Dios ("utrum Deum esse sit per se notum"), y polemice con la prueba anselmiana, destacará que muchos que han aceptado la existencia de Dios, no estarían dispuestos a admitir que es "el ser mayor que el cual nada puede concebirse" ("id quo maius significari non potest"), como aquellos que creyeron "Deum esse corpus" (I, q. 2, a. 2, ad 2), en abierta alusión al materialismo de los dos heresiarcas condenados a principios del siglo XIII.

20

Existe edición critica: N. WICKI (ed.), Philippi Cancellarii Parisiensis Summa de bono, FranckeVerlag, Bern 1985. La obra está estructurada en tres partes, precedidas por un prólogo sobre los trascendentales: 1) sobre el bien de la naturaleza, no disminuíble o disminuíble por el mal culpable; 2) sobre el bien en general; 3) sobie el bien de la gracia, que es la parte más extensa. Sobre este autor existe una monografia reciente: M.-M. HERVÁS-GÁLVEZ, El bien según Felipe el Canciller. La Summa de bono en el contexto de la recepción anistotélica, Eunate, Pamplona 1996.

21 Todo lo corporal tiene materia, de la cual se constituye. Esta era una tesis universalmente admitida y nos parece indiscutible, todavia ahora. En cambio, la tesis "todo lo material es corporal", entonces aceptada también como indiscutible por el hilemorfismo universal, de matriz más o menos agustiniana, sería posteriormente discutida y reprobada por Tomás de Aquino. 
situó, a nuestro entender, la Summa de bono, que aporta, además, el primer estudio detallado sobre los trascendentales. ${ }^{22}$

Otra "suma" marcó época, y a la cual ya nos hemos referido, es la Summa theologica o Summa halensis, ${ }^{23}$ también denominada Summa fratris Alexandri, compuesta entre 1243 y 1245. Fue empezada por Alejandro - convertido ya en fraile franciscano - Juan de la Rupella y Juan de Fidenza (San Buenaventura). A la muerte de Alejandro y de Juan de la Rupella, en 1245, fue continuada por Buenaventura, que también la abandonó; tampoco la terminó Guillermo de Melitona que había seguido el trabajo interrumpido por Buenaventura. (La intemupción definitiva se produjo en la parte tercera del libro tercero, cuando debía comenzar la exposición de los artículos de la fe). Está inspirada en las Sentencias de Pedro Lombardo, y en las Summae de Guillermo de Auxerre y de Felipe el Canciller, sobre todo en lo referente a la gratologia o tratado de la gracia santificante. ${ }^{24}$

El tractatus introductionis de la Summa halensis es notable, sobre todo la primera cuestión, que se plantea, ya en perfecta sintonía con el ambiente peripatético que se respiraba en París, si la Teología es o no ciencia (en sentido aristotélico). En la segunda cuestión se pregunta si es posible, y cómo, el conocimiento de Dios in via, tema que después veremos repetido en los manuales frnaciscanos de finales del XIII y a lo largo del XIV, desembocando en las complejas discusiones acerca de la posibilidad o no de la intuición intelectual de Dios in terris.

Entre las sumas también se puede citar el Breviloquium ${ }^{25}$ de San Buenaventura, escrito entre 1253 y 1257, al tiempo que enseñaba en la Universidad de París. Lo escribió a petición de algunos religiosos de su Orden, para que éstos pudieran conocer fácilmente y de modo sumario la sacra doctrina, incluso aquellos que no cursaran estudios universitarios. En la estructura de este opúsculo influye, sin

22 Sobre el origen de los trascendentales, y del papel relevante que le cupo en esta cuestión a Felipe el Canciller, cfr. J. A. AERTSEN, The Beginning of the Doctrine of the Transcendentals in Philip the Chancellor (ca. 1230), en "Mediaevalia. Textos e Estudos", 7-8 (1995) 269-286; e ID., Medieval Philosophy and the Transcendentals. The Case of Thomas Aquinas, E.J. Brill, Leiden-New YorkKöln 1996. -Conviene insistir en que el término "trascendental" es análogo. Aertsen lo emplea en varios sentidos. Por ejemplo; recuerda que, según Aquino, los trascendentales son seis: el ens y sus cinco propiedades trascendentales. Por consiguiente, no es lo mismo el "trascendental" que la "propiedad trascendental". También se ha dicho que el esse es "trascendental", que el tomismo es "trascendental" y, en el caso de Kant, que hay una estética "trascendental". Sobre este tema, cfr. E. FORMENT, La sistematización de Santo Tomás de los trascendentales, en "Contrastes. Revista Interdiciplinar de Filosofia", 1 (1996) 107-121.

23 Edición crítica: Summa theologica, Quaracchi 1924-1979, 6 vols., el último de ellos dedicado integramente a índices. Está estructurada en cuatro libros: 1) Dios en sí mismo; 2) Dios creador, la obra de la creación, las criaturas, y el pecado; 3) Encamación, ley, gracia, virtudes. En esta parte, comenzada la virtud de la fe, se interrumpe la obra. El cuarto libro debería haber tratado los sacramentos. Alejandro de Hales había escrito, en la década de los veinte, una Glossa Sententiarum a las Sentencias de Pedro Lombardo, que son de una calidad muy inferior a esta Summa, también publicadas por los editores de Quaracchi, de 1951 a 1957, en 4 vols.

Cfr. J. L. ILLANES y J. I. SARANYANA, op. cit., p. 51-53.

25

Existe edición critica: las Opera omnia de San Buenaventura, en 10 vols, Quaracchi 1882-1902. El Breviloquium se halla en el tomo quinto. Después de un prólogo sobre la Sagrada Escritura, desarrolla su obra en siete partes, estructuradas en capitulos: la Santisima Trinidad; la creación, con particular atención al hombre; la corrupción del pecado; la Encarnación; la gracia del Espiritu Santo, virtudes y dones; la medicina sacramental: los sacramentos en general y en particular; los novisimos. 
duda, el trabajo ya realizado anteriormente por el Seráfico en la Summa halensis. El Breviloquium es, además, contemporáneo del monumental comentario bonaventuriano a las Sentencias de Pedro de Lombardo, que ocupa los primeros cuatro gruesos volúmenes de la edición crítica de Quaracchi. Como se sabe, en efecto, el Seráfico había comenzado a leer "privadamente" las Sentencias lombardianas en 1245. En 1248, obtuvo autorización de sus superiores para hacerlo públicamente. Su magno comentario estaría, pues, terminado a finales de 1256, ya que en febrero de 1257 fue elegido general de los franciscanos, abandonando por completo todas sus tareas académicas (ni siquiera llegó a tomar posesión de la cátedra en la Universidad de Paris, que había ganado por concurso). Ambos trabajos, por tanto, el comentario y el Breviloquium son contemporáneos.

Como ya se ha dicho, el Breviloquio responde a la inquietud de Buenaventura por alcanzar una mejor sistematización de la doctrina sagrada, que facilitase su comprensión por parte de los discípulos; la misma inquietud que habría de embargar a Aquino algunos años después, y que movió a fray Tomás a comenzar su Summa theologiae. Buenaventura nos da una estructura lineal, que él mismo resume al comienzo de la obra. Son siete los tratados: Dios como principio de las cosas creadas; la creación misma; el pecado; la Redención obrada por Cristo; la "reforma" por la gracia santificante; la curación por los sacramentos; la retribución final (penas y gloria). ${ }^{26}$

El punto culminante de las "sumas" es, sin duda, la Summa Theologiae ${ }^{27}$ de Santo Tomás, escrita entre 1266 y 1273, con interrupciones y finalmente inconclusa. ${ }^{28}$ La idea de componer una Summa para "principiantes" puede habérsele ocurrido en 1265, cuando era maestro en el studium romano de Santa Sabina. Pero no debió de comenzar a trabajar en ella hasta 1266, cuando desechó definitivamente sus planes de reeditar, modificándolo, su comentario a las Sentencias de Pedro Lombardo. Se ha escrito muchísimo comentando la estructura de la Summa theologiae. Una obra clásica al respecto fue publicada, hace más de un cuarto de siglo, por el benedictino Ghislain Lafont. ${ }^{29}$ En todo caso, conviene recordar que Aquino arranca con una cuestión preliminar, seguramente inspirada por la Summa halensis, que es, in nuce, lo que después será el De locis de Melchor Cano. En esa primera cuestión ofrece una serie de consideraciones acerca de la condición cientifica de la Sagrada Doctrina o Teología. Sobre este tema epistemológico había es-

26 Breviloquium, prologus (Q. V, 208a-b).

La edición critica de la obras de Santo Tomás, comenzada por la Comisión leonina en 1882, no está concluida, pero incluye la Suma Teológica. Santo Tomás estructura su Suma en tres partes: 1) Dios en si mismo, la creación en general y en particular, y el gobiemo de todo lo creado; 2) la moral general y especial; 3) la cristologia y soteriologia, los sacramentos y los novísimos. Aunque la autoria de Santo Tomás termina en el sacramento de la penitencia - inacabado -, la estructura de esa parte estaba ya prevista; el resto de la penitencia, la extremaunción, el orden y el matrimonio, y los novisimos son reportaciones hechas por Reginaldo de Pipemo teniendo a la vista el comentario de Santo Tomás a las Sentencias de Pedro Lombardo. Sobre la cronología de las obras aquinianas, cfr. J. A. WEISHEIPL, Tomás de Aquino. Vida, obra y doctrina, trad. cast., EUNSA, Pamplona: 1996.

29 G. LAFONT, Estructuras y método en la "Suma Teológica" de Santo Tomás de Aquino, trad. cast., Rialp, Madrid 1964. Véase tambièn, aunque más modesta y más antigua, pero igualmente valiosa, la monografia de M. GRABMANN, La Somme théologique de Thomas d'Aquin. Introduction historique et practique, Nouvelle Librairie Nationale, París: 1925. 
crito con anterioridad él mismo, durante su primera regencia parisina, al comentar el De Trinitate de Manlio Severino Boecio. ${ }^{30}$

La Summa theologiae aquiniana se divide en tres partes (la segunda parte, en dos subpartes). Primera parte: estudia la unidad de la esencia divina y la trinidad de Personas; la creación en general y en particular, con especial atención al hombre. Segunda parte, la más extensa, ofrece su antropología, ética, moral y tratado místico. La tercera parte, inconclusa, que se abre con la cristologia y se continúa con los sacramentos (debería de haber terminado con los novisimos).

\section{3 - Esquema general de las sumas}

Por la brevedad de este estudio no se entrará en la metodología propiamente, sino que se considerará solamente el esquema de las distintas obras. Se pretende examinar, a la vista de los esquemas, cómo evoluciona la sistematización, teniendo presente el Systemgedanke. Una primera aproximación se centrará en el modo de concebir el esquema, su hilo conductor en el modo de presentar toda la sacra doctrina.

Hugo de San Víctor eligió, para sus dos "sumas", un esquema que, como ya hemos señalado, sigue prácticamente la historia de la salvación. La estructura de su De sacramentis christianae fidei no está todavía muy depurada, pues presenta abundantes repeticiones, como se advierte con sólo asomarse a su ordo rerum.

Otras estructuras se podrían llamar temáticas - aunque no conceptuales - y fuertemente especulativas. Son la Summa sententiarum, la Summa aurea de Guillermo de Auxerre, la Summa halensis y, sobre todo, la Summa theologiae de Santo Tomás. El Systemgedanke aquí podria ser exitus-reditus: Dios en sí mismo, la creación, la "vuelta" a Dios por parte del hombre a través de Cristo y los sacramentos. ${ }^{31}$

El esquema del Breviloquium de San Buenaventura podría llamarse históricotemático, nucleándose a partir de la idea de la scientia sapita que preside el desarrollo de los temas. Para el Seráfico, la teología es ut boni fiamus. ${ }^{32} \mathrm{Su}$ sintesis arranca de la Santisima Trinidad y termina en los novísimos o postrimerías, siguiendo el ciclo de la historia de la salvación, aunque con una fuerte acentuación

- temática, como ya hemos señalado en su momento, al presentar este opúsculo.

30 El titulo del opúsculo es: In Boëthii de Trinitate, también conocido como Opusculum 70. Dos hermenéuticas opuestas sobre esta obra son: M. GRABMANN, Die theologische Erkenntnis-und Einleitungslehre des hl. Thomas von Aquin auf Grund seiner Schrift "In Boethium de Trinitate", Paulus Verlag, Freiburg in der Schweiz 1948; y el libro ya citado de M. D. CHENU, La Théologie comme science, J. Vrin, Paris 1927. Véase también, con el estado de la cuestión: J.I. SARANYANA, Grandes maestros de la teologia, Atenas, Madrid, 1994, p. 121-131.

31 El esquema "exitus-reditus" ha sido popularizado por M.D. CHENU, Introduction à saint Thomas d'Aquin, op. cit., p. 261. Recientemente se ha intentado un esquema evangélico en la Summa aquiniana (Cristo como camino, verdad y vida). Cfr. F. GABORIAU, Le projet de la Somme idée pour notre temps, FAC-Éditions, Paris: 1996.

32 Sobre la polémica parisina acerca del carácter especulativo o sapiencial de la ciencia teológica, cfr. J.I. SARANYANA, La polémica parisina sobre la condición científica de la Teologia (1250-1270), en VV. AA., Biblia, exégesis y cultura. Estudios en honor del Prof. D. José $M^{2}$ Casciaro, EUNSA, Pamplona: 1994, p. 659-678. 
Las Sententiae de Pedro Lombardo tienen una estructura original, inspirada en San Agustín: está dividida en de rebus y de signis. Entre las res distingue las realidades que son objeto de frui (Dios en su unidad y trinidad de Personas) y las que son objeto de uti (la obra de la creación) y finalmente la realidad objeto de frui-uti (el Verbo encarnado). Dentro de los signa están comprendidos los sacramentos, a los que se añaden los novísimos. Se puede considerar un Systemgedanke antropológico, con una perspectiva vocacional-finalista del hombre.

Una idea sistematizadora completamente distinta encontramos en la Summa de bono de Felipe el Canciller: el bien, considerado en toda su amplitud, natural y sobrenatural. Este planteamiento es completamente distinto del de otras sumas y sorprende inicialmente, pero se comprende desde su contexto histórico. Esta obra se escribe aproximadamente a los diez años de haberse celebrado el Concilio IV de Letrán que, con el decreto Firmiter cerró - al menos doctrinalmente - la polémica dualista precedente y destacó la bondad de toda la creación. ${ }^{33}$

Este examen somero de la estructura de las sumas seleccionadas permite concluir que existía una "forma interna" en la mente de los distintos autores, diferente en cada caso, aunque se pueden establecer paralelismos. Este Systemgedanke se remonta a veces claramente a una fuente concreta, como en Pedro Lombardo; otras veces es un enfoque histónico - de la historia de la salvación; en otros casos está movido por unas circunstancias histórico-doctrinales, o influido por un modo determinado de concebir la teología.

\section{4 - El tratamiento de algunos temas en las sumas pleno-medievales}

Desde el punto de vista sistemático resulta interesante examinar cómo - en qué contexto y con qué extensión - son tratados algunos temas teológicos en el conjunto de cada una de las obras que hemos presentado.

a) Consideremos, en primer lugar, la teología trinitaria, teniendo en cuenta la polémica levantada por Joaquín de Fiore contra Pedro Lombardo, que fue objeto de una decisión magisterial en el IV Concilio Lateranense. ${ }^{34}$ Interesa, concretamente, si se parte de la esencia para llegar a la trinidad de Personas, o se concede preferencia a la doctrina sobre las Personas en detrimento del tema de la unidad esencial y de los atributos esenciales.

Una comparación meramente estructural de las sumas que hemos elegido exceptuando a la Summa de bono que se limita a unas pequeñas referencias trini-

33 DS 800, dentro del cap. 1² De fide catholica, 800-803. Cfr. M. M. HERVÁS-GÁLVEZ, op. cit., p. 1719.

34 Damnamus ergo (DS 803-808). Sobre la condena del IV Lateranense, cfr. J. I. SARANYANA, Joaquín de Fiore y Tomás de Aquino. Historia doctrinal de una polémica, Eunsa, Pamplona; 1979. En un iibro titulado De unitate seu essentia Trinitatis, atribuido entonces al Abad Florense, se acusaba al Lombardo de sostener la cuaternidad divina (las tres personas divinas y la res o esencia). El Concilio salió en defensa de la ortodoxia del Maestro de las Sentencias, declarando que la summa res o esencia "veraciter est Pater, et Filius, et Spiritus Sanctus". Por consiguiente, en Dios sólo hay Trinidad; en ningún caso cuaternidad. La afirmación de que el Padre se identifica realmente con la esencia, lo mismo que el Hijo con ella, y el Espíritu Santo con ella, siendo, a la vez, distintos realmente el Padre, el Hijo y el Espíritu Santo, constituye el meollo del misterio trinitario. 
tarias en diversos contextos de la obra - arroja ya alguna luz sobre el tratamiento de la doctrina trinitaria.

En el De sacramentis christianae fidei de Hugo de San Victor, por ejemplo, no hay todavia un tratamiento preferente de la unidad de esencia en comparación con la trinidad de Personas. Es más: el tratado de Trinitate es pobre, y aparece sólo cuando se estudia la condición racional del hombre como vestigio de la Trinidad (tema, evidentemente, muy agustiniano). En Hugo, pues, se la lleva la palma el análisis de la esencia divina, todo él en el primer libro de esa "suma", que se corresponde con la Antigua Alianza. Es lógico, pues, que, en tal contexto, la Trinidad divina tenga poco relieve, puesto que la revelación perfecta de este misterio tuvo lugar en Cristo.

Conforme avanza el tiempo, se percibe cierta predisposición a tratar primero y más ampliamente de la trinidad personal. Esto lo apreciamos ya en la Summa sententiarum, cuya estructura es muy curiosa: después de presentar las virtudes teologales, ofrece la trinitología, seguidamente el estudio de los atributos esenciales y, finalmente, la cristología. Todo ello en el "tractatus primus".

En Pedro Lombardo aparece, después de su famoso prólogo, el tratado trinitario completo, antecediendo al estudio de la esencia divina, cuya directa consideración no comienza hasta bien entrado el libro primero, concretamente hasta la distinción xxxiii.

En cambio, en la Summa aurea, o sea medio siglo más tarde, se ha invertido ya el esquema. La Summa fratris Alexandri, que data de 1245, ofrece un ejemplo paradigmático de cuanto acabamos de decir: en el libro primero, primera parte, publica seis extensos tratados sobre la unidad de la esencia divina, a los que sigue un único tratado dedicado a las dos procesiones divinas inmanentes. El libro primero, segunda parte, está dedicado a los nombres divinos, tanto los que se refieren a la esencia divina como los que se refieren a las personas divinas o se predican de ellas (propiedades, relaciones y nociones). ${ }^{35}$ Este esquema adquiere un desarrollo notable en la Summa Theologiae de Santo Tomás.

Tal preferencia metodológica (primero la unidad de la esencia y después la Trinidad de Personas) no implica, obviamente, un abandono del tratado trinitológico. Incluso algunos, como Buenaventura, coautor de la Summa alexandrina y contemporáneo de Aquino, antepone todavía, en su Breviloquio, el tratado trinitario al estudio de la esencia divina. La unidad de la esencia divina no se incluye, en efecto, hasta el capítulo quinto y, además, muy brevemente. En cambio, el Seráfico concede un relieve notable a muchos temas trinitarios dificiles y altamente

35 La neoescolástica ha sistematizado las propiedades de las personas divinas de la forma siguiente: dos actos nocionales (por los cuales se "producen" las personas divinas según procedencia), que son la generación y la espiración pasiva; tres propiedades personales (por las cuales se constituyen las personas divinas), que son la paternidad, la filiación y la espiración pasiva (la espiración activa no es propiedad en sentido estricto, pues conviene al Padre y al Hijo conjuntamente); cinco nociones (que son caracteres propios por los cuales las personas divinas se conocen como distintas y se distinguen entre sí), que son innascibilidad y paternidad, filiación, espiración pasiva, y espiración activa (común al Padre y al Hijo). También se ha distinguido entre nombres propios (que son los que convienen a una persona y hay que negarlos de otra) y nombres apropiados (que son comunes a las tres personas, aunque se prefiere atribuirlos a una de las personas, según los casos). Por ' ejemplo, el Hijo se llama propiamente Verbo, y apropiadamente, Sabiduría. 
especulativos, de los cuales quizá podría haber prescindido en una obra tan resumida como es el Breviloquio. Tal es el caso de su capitulo tercero de la primera parte. Alli estudia las dos "emanationes" de las personas (per modum naturae et voluntatis, es decir, lejos del planteamiento de Tomás de Aquino), las tres "hypostasis", las cuatro "relationes" (patemitas, filiatio, spiratio, processio), las cinco "notiones" (las cuatro relaciones más la innascibilitas) y las tres "proprietates personales" (Pater, Filius, Spiritus Sanctus).

Posiblemente haya influido en el giro metodológico, que si no fue total, se impuso casi por completo, la decisión del Concilio IV de Letrán, que aportó nueva luz y seguridad sobre la doctrina trinitaria, particularmente al cerrar la polémica sobre la relación de la esencia divina respecto de las Personas. Es posible que los teólogos hayan apreciado, releyendo el decreto Damnamus ergo del Lateranense, que una opción metodológica en la que primase la esencia sobre las personas resultaba más clara para los alumnos, evitando el riesgo de la cuaternidad, que supuestamente Joaquín de Fiore había achacado al Lombardo. Sin embargo, y desde el punto de vista "afectivo", o sea, desde la perspectiva dela vida espiritual, es evidente que psicológicamente resultaba más fácil iniciar el estudio a partir de las personas divinas. Quizá por ello, San Buenaventura prefirió la vía trinitológica, puesto que la Teología era, para él, una ciencia ut boni fiamus. ${ }^{36}$

b) Conviene considerar también el origen y desarrollo del tratado de homine en las sumas seleccionadas. Concretamente interesa si este tema se trata dentro del contexto natural de la creación, o en el de creación-elevación, o en ambos.

Generalmente se sitúa la doctrina sobre el hombre en un contexto de creación-elevación. Es el caso de la obra de Hugo de San Víctor, de la Summa sententiarum, de las Sentencias de Pedro Lombardo, de la Summa aurea y de la Suma halense.

El Breviloquio desarrolla su antropología en el contexto de la elevación, pasando después - en la tercera parte de la obra - al origen del mal en general y en particular el pecado del hombre (el de los ángeles lo había considerado unido a la creación y elevación de ellos).

En cambio, Felipe el Canciller estructura su antropología en dos partes distintas. La primera - la antropología natural - se encuentra dentro del tema De bono nature, no disminuible por el mal de culpa. La segunda parte trata del hombre en el contexto de la elevación ( $D e$ bono nature quod est diminuibile per malum culpe), es decir, la justicia original y su pérdida por el pecado, y puntualiza seguidamente que la bonitas naturalis anteriormente expuesta puede ser disminuida en parte por el pecado.

También Santo Tomás desarrolla su antropologia en diversos contextos: al hombre en sí, dentro de la creación natural, dedica las qq. 75 a 93 en la primera

36 La discusión sobre el carácter especulativo o práctico de la ciencia teológica recorre todo el Bajo Medievo, llegando a la segunda escolástica. La costumbre, por ejemplo en la Universidad de Salamanca de finales del siglo XV, era contraponer a Aquino con Buenaventura en esta cuestión disputada. Cfr. J. I. SARANYANA, Santo Tomás de Aquino y San Buenaventura frente al "mal uso" (Ms 52, fol. 1v, de la Catedral de Pamplona), en "Rivista di Filosofia neo-scolastica", 68 (1976/2) 189-214. 
parte de la Suma, culminando su antropologia en la doctrina sobre la imagen de Dios en el hombre. Seguidamente trata del estado de justicia (qq. 94 a 102), es decir el hombre elevado sobrenaturalmente. En cambio, la caída del hombre es tratada en la I-II, en el contexto del pecado.

c) Otro aspecto interesante para la historia de la teologia sistemática es el tratado de la gracia ut talis, es decir claramente diferenciado y no considerado simplemente al hilo de otros temas.

En De Sacramentis aparece la gracia en un contexto cristológicoeclesiológico, en cuanto gracia dada por Cristo en su Cuerpo que es la Iglesia. La Summa sententiarum no trata específicamente de la gracia. Pedro Lombardo la incluye dentro de la creación, concretamente dentro de la antropología. Guillermo de Auxerre menciona la gracia en varios contextos - Jesucristo, la caridad, la justificación - pero no tiene propiamente un tratado sobre la gracia.

El Breviloquio aporta un pequeño tratado de la gracia, en la quinta parte de la obra, entre la Encarnación y los sacramentos. Dentro del mismo apartado sobre la gracia incluye también otros temas relacionados con la vida de la gracia como las virtudes, los dones, las bienaventuranzas, los preceptos y consejos, y la oración.

Felipe el Canciller tiene un tratado sobre la gracia ut talis - de bono gratie -; la gracia en general, en los ángeles y - ampliamente - en el hombre, distinguiendo entre gratia gratis data y gratia gratum faciens; distingue también entre la gracia y las virtudes, de las que habla seguidamente.

La Summa halensis sitúa la gracia en el tercer libro - sobre la Encarnación y la moral. Desarrolla propiamente un tratado de la gracia, estructurado en dos partes: de gratia gratum faciente, muy extenso (existencia y necesidad, esencia, división, sujeto, causa y efectos, conocimiento de la gracia y distinción respecto de las virtudes, dones y frutos; el mérito se considera implícitamente); y de gratia gratis data, en general y en especial (en este segundo apartado incluye las virtudes - la fe, donde se interrumpe la redacción en 1245). El tratado de la gracia, por tanto, es obra todavía del primer equipo redactor.

La Summa Theologiae de Santo Tomás contiene un tratado de la gracia, ya muy estructurado y extenso, situado dentro de la I-II, que trata de la moral general. Abarca de la q.101 a la q.114, exponiendo esta última el mérito. Santo Tomás dedica estas cuestiones estrictamente a la gracia: su necesidad, esencia, división, causa y efectos.

d) Finalmente conviene examinar cómo está concebida en estas obras la cristología y los sacramentos.

En Hugo de San Víctor encontramos la cristologia en el segundo libro (opus restaurationis), y en el mismo contexto la Iglesia y los sacramentos: el sacramento del orden junto con el tema de la Iglesia y seguidamente los otros seis. De los sacramentos en general había tratado ya en el primer libro (opus conditionis) en el contexto de la reparación del pecado.

La Summa sententiarum sitúa la cristología en el primer libro, siguiendo al tratado trinitario. Los sacramentos en general figuran en el cuarto libro junto a la 
fe; y los sacramentos singulares se tratan en los libros quinto a séptimo, teniendo en cuenta que el orden fue añadido posteriormente por otros autores.

Pedro Lombardo dedica el tercer libro de las Sentencias a la cristología y soteriologiá, según el esquema agustiniano ya mencionado, y expone la doctrina sobre los sacramentos en el cuarto libro.

La Suma de Guillermo de Auxerre sitúa la cristología - no muy extensa - al principio del tercer libro, seguido de la moral que ocupa la mayor parte. Los sacramentos están incluidos en el cuarto libro - una parte general, histórica, y luego cada uno de los sacramentos - seguidos de los novísimos.

La Summa halensis contiene un tratado muy extenso y estructurado, dentro del tercer libro, tratando de la Encarnación, de la Persona y de la vida de Cristo. La parte prevista para los sacramentos no se llegó a redactar, pero iba a ocupar un tratado aparte, en el cuarto libro.

Felipe el Canciller no tiene propiamente tratado de cristología ni de los sacramentos.

El Breviloquio expone la cristología y los sacramentos en dos pequeños tratados separados: la cristología, en la cuarta parte, entre la corrupción del pecado y la gracia del Espíritu Santo; y los sacramentos entre la gracia y los novísimos.

Santo Tomás concibe una unidad temático-causal entre Cristo y los sacramentos, de modo que ambos análisis ocupan prácticamente toda la tertia pars. Primero Cristo (Encarnación y Redención), y luego los sacramentos, en general, y cada uno en particular. Con todo, la ubicación de la cristología aquiniana en la Summa ha supuesto no pocos problemas. Muchos estiman que su deslizamiento fuera de la segunda parte, donde se estudia ampliamente el camino sobrenatural del hombre hacia Dios, estaría motivado por una cuestión ella misma cristológica. En pocas palabras: supuesta la doctrina tomasiana sobre el motivo formal de la Encarnación (propter nos homines y propter nostram salutem), y supuesto que Dios podria haber salvado por otras vías, pero nunca sin la gracia santificante, es decir, nunca sin elevarnos al orden sobrenatural, la Encarnación de Cristo, con ser el hecho más extraordinario de nuestra historia (la plentud de la historia), sería algo no "necesario" absolutamente, como tampoco los sacramentos. Solamente necesarios, supuesto que Dios previó salvarnos exigiendo una perfecta satisfacción de su justifica divina.

\section{5- Algunas conclusiones}

El trabajo realizado permite ya sacar algunas conclusiones, que, evidentemente no son definitivas, pero pueden ser de interés para futuras investigaciones, sobre todo si se pretende estudiar la génesis de los grandes tratados sistemáticos, tanto dogmáticos como morales.

Cronológicamente se constata, en primer lugar, un esfuerzo noțable de sistematización, más allá de los comentarios biblicos y de la recogida ordenada de las sententiae Patrum. Nos encontramos ante los comienzos y el primer desarrollo de la teología sistemática. En esta evolución ha influido sin duda la aplicación de la lógica aristotélica a la estructuración de la sacra doctrina. 
En segundo lugar, se aprecia, ya desde el primer tercio del siglo XII, el esfuerzo por encontrar una idea sistematizadora o un determinado punto de vista bajo el cual considerar la sacra doctrina en su totalidad y, en este sentido, se ha hablado de Systemgedanke. Este tiene una función unificadora, sin forzar por eso el cuerpo de doctrina que se transmite. Este Systemgedanke puede variar mucho entre los distintos autores, desde una consíderación histórica hasta un punto de mira determinado, como lo es el bien en la Suma de Felipe el Canciller; pero, desde el IV Lateranense, en el sustrato de todos los Systemgedanken subyace la dialéctica con la definición aristotélica de "ciencia".

Por último es interesante observar cómo se van formando los distintos tratados que integran la teología, y cómo están enfocados. El tratado trinitario, por ejemplo, está constituido desde el principio, seguramente por influencia del De Trinitate agustiniano. Después de muchas vacilaciones, que abarcan todo el siglo XII, se aprecia un mayor equilibrio entre la importancia que se concede al estudio de la esencia divina y el de las Personas. Es posible que haya pesado sobre las opciones metodológicas del siglo XIII, el decreto Damnamus ergo del IV Lateranense. Otros tratados, como el de la gracia o el de homine, se empiezan a constituir como tales, unificando en una consideración sistemática las diversas referencias esparcidas por otros contextos.

La discusión sobre la ubicación de la cristologia (junto al estudio de la caída del hombre y la reparación del pecado, o bien al final de las "sumas"), implica claras opciones teológicas, que afectan, no sólo a la misma cristología, sino también al tratado de creatione y a la soteriología. 